\title{
Enhancement of pigment production potential of Serratia marcescens (GBB151) through mutation and random amplified polymorphic deoxyribonucleic acid analysis of its mutants
}

\author{
Cecilia Nireti Fakorede ${ }^{1 *}$, Babamotemi Oluwasola Itakorode ${ }^{2}$, Olu Odeyemi ${ }^{3}$, Gbolahan Babalola ${ }^{3}$ \\ ${ }^{1}$ Department of Biological Sciences, College of Natural and Applied Sciences, Oduduwa University Ipetumodu, Osun State, Nigeria, ${ }^{2}$ Department of Chemical \\ Sciences, College of Natural and Applied Sciences, Oduduwa University Ipetumodu, Osun State, Nigeria, ${ }^{3}$ Department of Microbiology, Faculty of Science, \\ Obafemi Awolowo University, Ile-Ife, Osun State, Nigeria
}

\begin{tabular}{l}
\hline ARTICLE INFO \\
\hline Article history: \\
Received on: December 17, 2018 \\
Accepted on: January 29, 2019 \\
Available online: July 04, 2019 \\
\hline Key words: \\
Pigment, \\
Random amplified polymorphic \\
deoxyribonucleic acid-polymerase \\
chain reaction, \\
Mutagenesis, \\
Serratia marcescens, \\
Ethidium bromide
\end{tabular}

Ethidium bromide

\begin{abstract}
Serratia marcescens (GBB151) was isolated and genetically modified for high-yielding pigment production capacity that could be employed for industrial purposes. Ethidium bromide-induced mutagenesis of GBB151 resulted in the generation of eight mutant isolates (GBB151Ea-GBB151Eh). The chemical mutants of $S$. marcescens obtained produced 5-fold more pigment than the wild-type organism. The wild-type GBB151 produced 413.9 unit/cell, while the mutant strains produced pigments with yields ranging from 841.7 to 2008.5 unit/cell. Random amplified polymorphic deoxyribonucleic acid-polymerase chain reaction analysis showed different amplicons patterns of native as well as mutant derivatives. The factorial analysis diagram and the dendrogram showed a degree of dissimilarity among the wild-type bacterial isolate GBB151 and its mutants. Mutant strains GBB151Ec and GBB151Ef were closest to the wild type as they appeared in the same quadrant. GBB151Ed which had lost its ability to produce pigment was farthest and in the different quadrant to the wild type. These study provided insight into improvement in pigment production by manipulating genetic make-up of $S$. marcescens, thus meeting industrial demand.
\end{abstract}

\section{INTRODUCTION}

Extracted pigments from living organism are termed biopigments [1]. Pigments are molecules that have color and are also materials that change the color of transmitted light due to wavelength-selective absorption. Coloring agents have been employed in foods, clothes, paintings, pharmaceuticals, cosmetics, and plastics. Color plays a prominent role in enhancing the esthetic appeal of foods [2] and other materials of commercial interest. The use of food colorants as an additive in the food industry is a significant factor for food manufacturers as well as consumers [3]. Due to the serious environmental and safety problems caused by many artificial synthetic pigments in food, cosmetics, textiles, and pharmaceutical products, research has concentrated on improving processes for the synthesis of safe and natural pigments from natural resources [4]. The demand for natural pigments has increased due to their applications in antioxidative activity, anticarcinogenicity, and positive effect on immune function [2]. There are many natural pigments, yet just

\footnotetext{
*Corresponding Author Cecilia Nireti Fakorede, Department of Biological Sciences, College of Natural and Applied Sciences,

Oduduwa University Ipetumodu, Osun State, Nigeria.

Email: olaniretifakoroede@yahoo.com
}

a few are accessible in adequate amount for industrial use because they are extracted from fruits, plant flowers, and leaves [5]. Common natural colors that are extracted from plant sources include annatto, saffron, paprika, caramel, beetroot, and turmeric [2]. Colors occur naturally in nature and the microorganisms that can produce different pigments which bring out these colors are quite common. Food grade pigments such as carotenoids, melanin, flavins, quinones and specifically monascins, violacein, and indigo are produced by microorganisms [6]. Monascus, Streptomyces, and Serratia have been shown to produce pigments [5]. Some bacteria produce pigments as part of their normal metabolism. The specific color of the pigment is characteristic for each bacterium. Several organisms can produce pigments (often termed biopigments) which are important classes of their secondary metabolites. Biopigments can be obtained from two major sources, namely plants and microorganisms [7]. Microorganism pigments are preferred to those from plants due to their relative stability [8] and the availability of their cultivation technology [5,9]. Biopigments from plants have numerous shortcomings such as non-availability and instability against adverse $\mathrm{pH}$, light, and low water solubility [10]. The various advantages of pigment production by microbes especially bacteria include independence from weather conditions, easy and faster growth in the cheap culture medium, and easy production of the pigments of different color shades. Pigments production by microorganisms is as at now one of the emerging fields of research 
to bring out their potentials for various industrial applications. In most previous studies on bacterial pigmentation, only a few out of so numerous bacteria that have been found to produce pigments have their pigments characterized and the bacteria identified to species level using biological molecular technology. There is a need, therefore, to study further pigments production by bacteria and to develop new strains that will produce a higher yield of pigments. Thus, the present study is designed to enhance pigment production potential of a bacterium strain through mutagenesis and then to genetically characterize its mutants.

\section{MATERIALS AND METHODS}

\subsection{Serratia marcescens (GBB1) Source and Isolation}

The bacteria strains were obtained from oxidation ponds of the Obafemi Awolowo University, Ile-Ife, Osun State (07.50907', $004.51267 '$ ). The ponds were being used to treat the domestic sewage from students' halls of residence and staff quarters before discharge and were located within the campus. Pour plate technique was adopted for the isolation of pigment-producing bacteria. 10-fold dilutions of the water samples were prepared with sterile distilled water ranging from $10^{-1}$ to $10^{-6} .1 \mathrm{ml}$ of the diluted samples from $10^{-3}$ to $10^{-6}$ were inoculated on nutrient agar and glycerol-supplemented composed agar. The plates were incubated aerobically at 30 and $37^{\circ} \mathrm{C}$ for $24-48 \mathrm{~h}$. The pure pigmented bacterial isolates were stored in a medium containing $50 \%$ glycerol at a temperature of $4^{\circ} \mathrm{C}$.

\subsection{Screening and Extraction of Pigment}

A loopful of an $18 \mathrm{~h}$ old test isolate was inoculated into a $5 \mathrm{ml}$ normal $(0.85 \%)$ saline and was standardized to 0.5 McFarland $(0.08-0.1 \times 105)$ cells per $\mathrm{ml}$ in a colorimeter at optical density of $590 \mathrm{~nm} .1 \mathrm{ml}$ of standardized cells suspension of the isolates were used to inoculate the pigment-producing media. The media consists of $100 \mathrm{ml}$ sterile nutrient broth in $250 \mathrm{ml}$ conical flask. The broth mixture was incubated in a shaking incubator with the speed of $120 \mathrm{rpm}$ for 24-48 $\mathrm{h}$ for pigment production.

Liquid culture medium was centrifuged at $7500 \mathrm{rpm}$ for $20 \mathrm{~min}$ supernatants were discarded while bacterial cell pellets containing the pigments were extracted with $95 \%(\mathrm{v} / \mathrm{v})$ methanol until the pellets became colorless. The bacterial cell pellets were washed in physiological saline and streaked on a nutrient agar plate to observe for growth and pigment production again (second generation) [11]. The pigment produced was estimated by the method described by Mekhael and Yousif, [12].

\subsection{Molecular Characterization of the Isolate}

The molecular analyses were carried out using molecular techniques and equipment available at the Bioscience Centre of the International Institute of Tropical Agriculture (IITA), Ibadan, Oyo State, Nigeria. Deoxyribonucleic acid (DNA) extraction from the bacterial isolates was carried out using a modified method of Trindade et al. [13]. Absorbance was measured at wavelengths of $260 \mathrm{~nm}$ and $280 \mathrm{~nm}$. Absorbance quotient gives an estimate of DNA purity. DNA concentrations from the different bacterial isolates were determined with a Nanodrop spectrophotometer (Beckman Coulter) and adjusted to $25 \mathrm{ng} / \mu 1$ for polymerase chain reaction (PCR) amplification.

\subsection{PCR Amplifications}

PCR amplification was performed in a total volume of $25 \mu \mathrm{l}$ containing $4 \mu \mathrm{l}$ of the DNA solution, $0.4 \mu \mathrm{l}$ of $10 \mathrm{mM}$
dNTPs, $2 \mu \mathrm{l}$ of $25 \mathrm{mM} \mathrm{MgCl}, 1 \mu \mathrm{l}$ of 10 pmol each of primer (forward 5'- CCAGCAGCCGCGGTAATACG -3' and reverse 5'-ATCGGCTACCTTGTTACGACTTC -3'), $0.24 \mu 1$ of Taq polymerase $(1 \mathrm{U} / \mu \mathrm{l})$ (Promega USA), and $5 \mu 1$ of $5 \times$ PCR buffer. Sterile DNase free water was added to make a volume of $25 \mu 1$. The PCR amplicons were visualized using $1.5 \%$ agarose gel electrophoresis.

\subsection{DNA Sequence Analysis}

Purified amplicons were centrifugation at $9000 \mathrm{rpm}$ before sequencing. ABI 3130xL Genetic Analyzer (Applied Biosystems, California, USA) available at the Bioscience Center of IITA, Ibadan, was used for the nucleotide sequencing. Sequence similarity search of the GenBank database was done using the NCBI Basic Alignment Search Tool (BLAST) program.

\subsection{Mutagenesis Experiments}

A stock solution $(10 \mathrm{mg} / \mathrm{ml})$ of mutagen (ethidium bromide) was prepared. Various concentrations $(200-400 \mu \mathrm{g} / \mathrm{ml})$ of ethidium bromide were used for the mutation of $S$. marcescens. $0.1 \mathrm{ml}$ of standardized cells suspension and $0.1 \mathrm{ml}$ of each concentration of ethidium bromide were inoculated into $9.8 \mathrm{ml}$ of nutrient broth. The test tubes were then incubated at $30^{\circ} \mathrm{C}$ for $24 \mathrm{~h}$. This was done to determine the subinhibitory concentration of the chemical agent on the different bacterial isolates [14,15]. $0.1 \mathrm{ml}$ of the standardized culture was inoculated into $9.9 \mathrm{ml}$ of nutrient broth, this serves as a control. At the end of incubation period, $0.1 \mathrm{ml}$ of each subinhibitory concentration of the mutagen was serially diluted in $9.9 \mathrm{ml}$ of nutrient broth and appropriate dilutions were plated on nutrient agar medium and incubated at $37^{\circ} \mathrm{C}$ for $24 \mathrm{~h}$. The survival rate of each bacterial isolate in chemical mutagen used was calculated as follows:

$\mathrm{S}=\frac{\text { Number of colonies with chemical mutagen }}{\text { Number of colonies without chemical mutagen (wild type) }} \times 100$

Where, $\mathrm{S}=$ Survival rate of each isolate in chemical mutagen.

\subsection{Random Amplified Polymorphic DNA (RAPD) Analysis}

The ethidium bromide-induced mutants of bacterial isolate GBB 151 were subjected to RAPD analysis to determine the molecular relatedness of the various mutants and the wild type. The RAPD analysis was also carried out at the same Institute. Primers were obtained from Inqaba Biotechnological Industries Limited, Pretoria, South Africa. 10 different random primers, each 10 nucleotides long, were used for RAPD. Each tube of PCR mix composed of $50 \mathrm{ng}$ DNA template, $1 \mu \mathrm{L}$ of $5 \mu \mathrm{M}$ a primer, $1.2 \mu \mathrm{L}$ of $25 \mathrm{mM} \mathrm{MgCl}_{2}$, $2 \mu \mathrm{l}$ of $10 \mathrm{mM}$ dNTPs, $1 \mu \mathrm{l}$ dimethyl sulfoxide, $0.2 \mu \mathrm{l}$ of $2.5 \mathrm{U}$ of Taq DNA polymerase (Promega, USA), $2.5 \mu 1$ of $10 \times$ buffer, and ultrapure water 15.1 to make a total volume of $25 \mu \mathrm{l}$. PCR products were electrophoresed on $1.5 \%(\mathrm{~W} / \mathrm{V})$ agarose gels, in $1 \times$ Tris borateEDTA buffer at $100 \mathrm{~V}$ for $5 \mathrm{~h}$ and then stained with ethidium bromide $(1.0 \mu \mathrm{g} / \mathrm{ml})$ [16]. Gels with amplification band profiles were visualized and photographed under UV light.

\subsection{Statistical Analysis}

All values were expressed as means and standard errors of means. The Students' $t$-test was used for comparison of the experimental groups. The level of significance was set at $P<0.05$ using one-way analysis of variance. 


\section{RESULTS AND DISCUSSION}

The bacteria strain was identified as $S$. marcescens (GBB151). It shared $96 \%$ homology with $S$. marcescens KM093865. The wild bacterial isolate GBB151 cultured at $30^{\circ} \mathrm{C}$ produced maximal (413.9 unit/cell) pinkish-red pigment at $30 \mathrm{~h}$ of incubation. Production of pigments by several bacteria strains has been reported $[5,6]$. This result corroborates Linawati et al. [17] on the influence of environmental condition on the production of pigment by $S$. marcescens. They observed that the peak of pigment production was achieved at late stage of growth and that there was a progressive decline in the yield of pigment after $30 \mathrm{~h}$ of incubation. Mutagenesis experiment was carried out by treating $S$. marcescens conidial suspension with different doses of ethidium bromide for $24 \mathrm{~h}$. Exposure of conidia to mutagen produced eight mutant strains (GBB151Ea, GBB151Eb, GBB151Ec, GBB151Ed, GBB151Ee, GBB151Ef, GBB151Eg, and GBB151Eh) of different morphological and biochemical characteristics. The different morphological characteristics of the mutants are shown in Figure 1. Seven of the mutants still retained its pigment producing potential while mutant GBB151Ed lost its ability to produce pigment. The pigment production by the wild type and mutants of GBB151 showed an impressive improvement in the latter than the former. There was a 5 -fold increase in the pigment produced by mutant strain GBB151Eb (2008.5 unit/cell) to that of wild-type GBB151 (413.9 unit/cell) which was statistically significant at $P \leq 0.05$. Furthermore, mutant GBB151Ec gave a 4-fold increase over the wild type. The results showed better performance by all the mutant strains than that obtained by the wild type in prodigiosin production. The influence of chemical mutagens on biopolymer producing strains was reported by Sreeju et al. [18]. Overexpression of cellulase through mutation of Trichoderma viride was reported by Shazia et al. [19]. In their study, the mutant strains of $T$. viride provide exponential increase in cellulolytic activity compare to wild strain. The yield (unit/cell) of pigment produced by each mutant and the wild type is presented in Figure 2. Seminar result was obtained by Gulani et al. [10] who reported the increase in prodigiosin yield of 811.88 unit/cell by the mutant bacteria strains. The improved productivity by the mutant strains could be attributed to genetic variations in the genes coding for pigmentation as a result of insertions and deletions of certain bases during mutations.

RAPD technique was employed to evaluate the genetic diversity of native and mutant genotypes. 10 different random primers, each 10 nucleotides long, were used for RAPD. Five primers (OPB 01, OPB 03, OPB 11, OPT 01, and OPT 10) were able to produce amplified band profiles in the genomic DNA of all the organisms (wild type and mutants), the other remaining five (OPB 10, OPB 17, OPT 20, OPT 06, and OPT 17) did not produce such amplification in all the organisms. A total of 297 bands were resolved by the 10 primers, $211(71.0 \%)$ of which were polymorphic while 86 (29.0\%) were monomorphic. Thus, each primer produced an average number of 29.7 bands, the size of which ranged between 180 and $3000 \mathrm{bp}$. The maximum number of bands (49) was produced by primer OPB 01 while primers OPT 06 and OPT 17 afforded the minimum number (17). One (1) DNA fragment of $850 \mathrm{bp}$ produced by primer OPB 11 and two (2) DNA fragments of $650 \mathrm{bp}$ and $450 \mathrm{bp}$ produced by primer OPT 10 were specific to isolate GBB151Ed alone which had lost the gene for pigment production. The numbers and sizes of DNA fragments produced by the RAPD primers are as presented in Table 1.

The high percentage polymorphism produced by primer OPB10 indicated that all the mutant genotypes portrayed different patterns of DNA amplification in contrast with the wild strain [Figure 3a]. Furthermore, RAPD primers OPB 01, OPB 11, and OPT 10 produced
18 monomorphic bands each [Figure 3b]. The results showed that chemical mutants were significantly different from wild type. This practice has been used by several researchers to develop a mutant through random mutagenesis [20-22]. Sreeju et al. [18] distinguished strains within species of Escherichia coli, Ralstonia eutropha, Pseudomonas putida and, and Bacillus megaterium after exposure to the chemical mutagen and UV radiation using RAPD fingerprinting technique. Kawar et al. [23] also used the RAPD markers for the assessment of genetic diversity in sugarcane cultivars. Each RAPD primer randomly complemented and amplified on the genomic DNA of the bacterial strains where the homologous sequence of the primer was found and at such distances, amplified DNA fragments or bands are generated. Some of the RAPD primers used were unable to randomly find homologous sequence in the genomic DNA of some bacterial strains and, therefore, could not produce any amplified DNA band in such bacteria.

The clearly resolved DNA fragments or bands produced by each RAPD primer used were scored manually for their presence (1) or absence (0) across the genotypes of the isolates and assembled in a binary data matrix table. The data on the resolved bands generated from the five primers (OPB 01, OPB 03, OPB 11, OPT 01, and OPT 10) which showed bands for all the isolates were used to estimate genetic dissimilarity among the genotypes based on Darwin Software

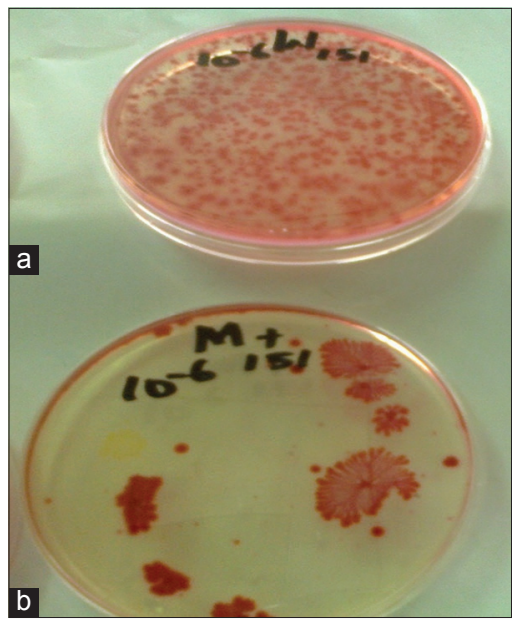

Figure 1: Colonies of GBB151 wild type and mutants on nutrient agar. (a) GBB151 wild-type colonies, (b) GBB151 mutant strains colonies

Table 1: RAPD primers and their properties in GBB151 wild type and mutant strains

\begin{tabular}{llccccc} 
Primer & Sequences & TB & MB & PB & PP(\%) & BR (bp) \\
OPB 01 & 5' GTTTCGCTCC 3' & 49 & 18 & 31 & 63.3 & $300-3000$ \\
OPB 11 & 5' GTAGACCCGT 3' & 45 & 18 & 27 & 60.0 & $180-2000$ \\
OPB 03 & 5' CATCCCCCTG 3' & 33 & 09 & 24 & 72.7 & $450-2000$ \\
OPB 10 & 5' CTGCTGGCAC 3' & 30 & - & 30 & 100 & $300-2000$ \\
OPB 17 & 5' AGGGAACCAG 3' & 23 & 08 & 15 & 65.2 & $650-2000$ \\
OPT 01 & 5' GGGCCACTCA 3' & 27 & - & 27 & 100 & $400-3000$ \\
OPT 20 & 5' GACCAATGCC 3' & 23 & - & 23 & 100 & $850-3000$ \\
OPT 06 & 5' CAAGGGCAGA 3' & 17 & 08 & 09 & 52.9 & $650-2000$ \\
OPT 17 & 5' CCAACGTCGT 3' & 17 & 07 & 10 & 58.8 & $650-2000$ \\
OPT 10 & 5' CCTTCGGAAG 3' & 33 & 18 & 15 & 45.45 & $450-2000$ \\
\hline
\end{tabular}

TB: Number of bands amplified, MB: Monomorphic bands, PB: Polymorphic bands, PP: Percentage polymorphism, BR: Band range 


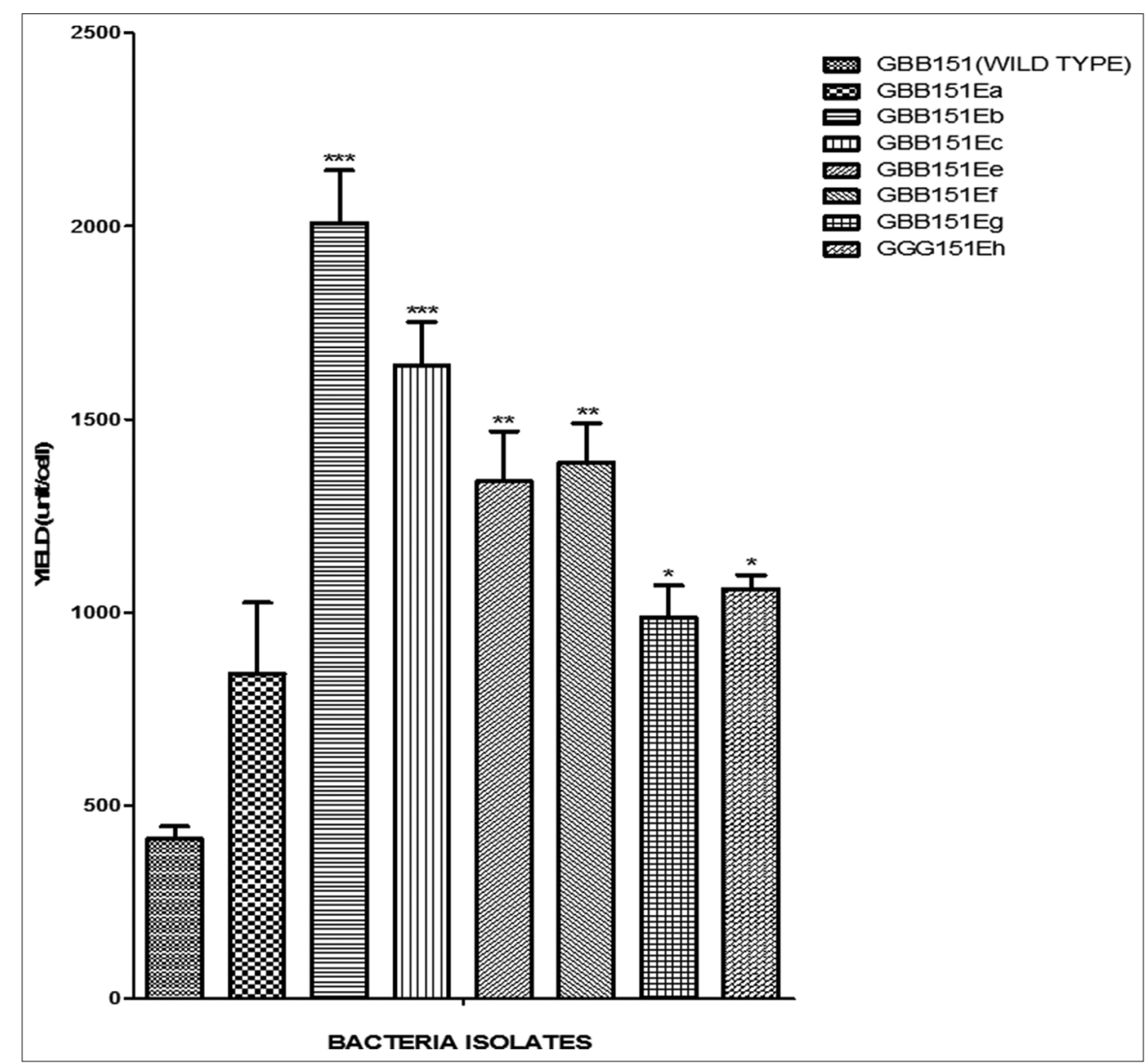

Figure 2: Yield of pigment produced by GBB151 wild type and mutants. *, **, *** indicate the degree of significance where *** shows the most significant effect

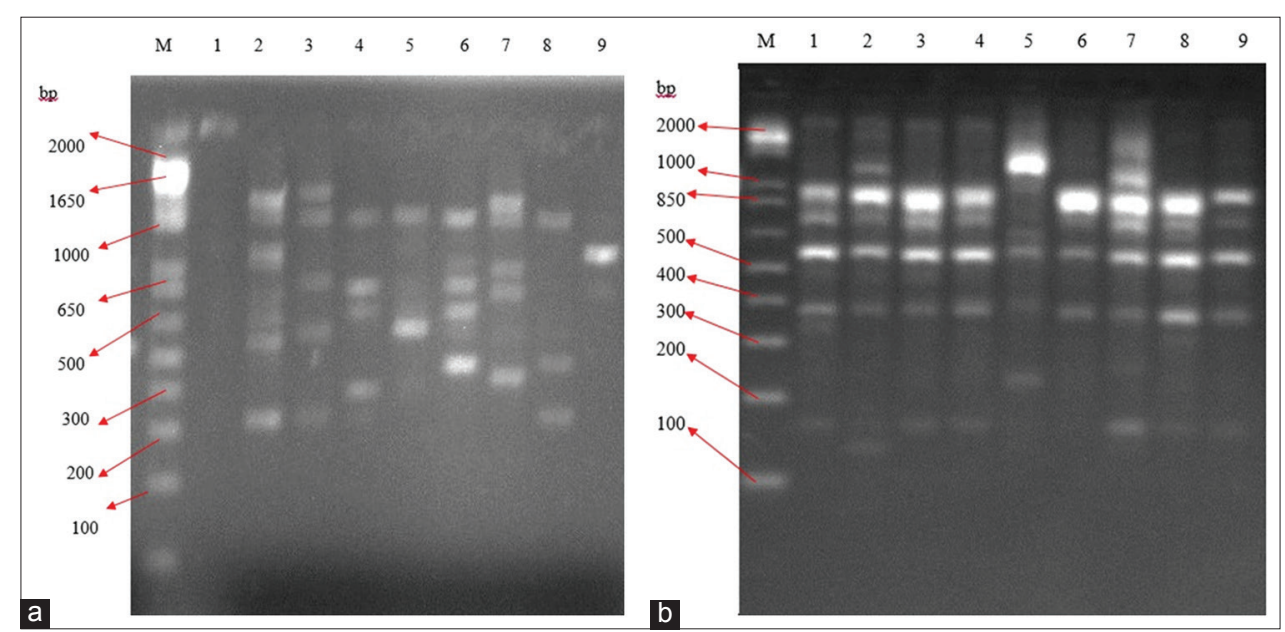

Figure 3: (a) Amplified DNA fragments generated by primer OPB 10 showing polymorphism in GBB151 wild type and mutant strains. $M=$ DNA ladder, $1=\mathrm{GBB} 151 \mathrm{Ea}, 2=\mathrm{GBB} 151 \mathrm{~Eb}, 3=\mathrm{GBB} 151 \mathrm{Ec}, 4=\mathrm{GBB} 151 \mathrm{Wt}$ (Wild type), $5=\mathrm{GBB} 151 \mathrm{Ed}$ (non-colored mutant), $6=\mathrm{GBB} 151 \mathrm{Ee}, 7=\mathrm{GBB} 151 \mathrm{Ef}$, $8=$ GBB151Eg, $9=$ GBB151 (b) Amplified DNA fragments generated by primer OPB 11 showing monomorphism in GBB151 wild type and mutant strains, $\mathrm{M}=$ DNA ladder, 1 = GBB151Ea, $2=\mathrm{GBB} 151 \mathrm{~Eb}, 3=\mathrm{GBB} 151 \mathrm{Ec}, 4=\mathrm{GBB} 151 \mathrm{Wt}$ (Wild type), $5=\mathrm{GBB} 151 \mathrm{Ed}$ (non-colored mutant), $6=\mathrm{GBB} 151 \mathrm{Ee}$, $7=$ GBB151Ef, $8=$ GBB151Eg, $9=$ GBB151.

using Dice dissimilarity matrix. The factorial analysis diagram and the dendrogram showing the degree of dissimilarity among the wild-type bacterial isolate GBB151 and its mutants are presented in Figures 4 and 5. The dendrogram genetic analysis for identifying mutation using different RAPD primers revealed a moderate genetic variability among isolate GBB151 wild type (S. marcescens) and the mutant strains, thus proving the existence of mutations. The factorial analysis diagram revealed the distances of the mutant strains from the wild-type strain. 


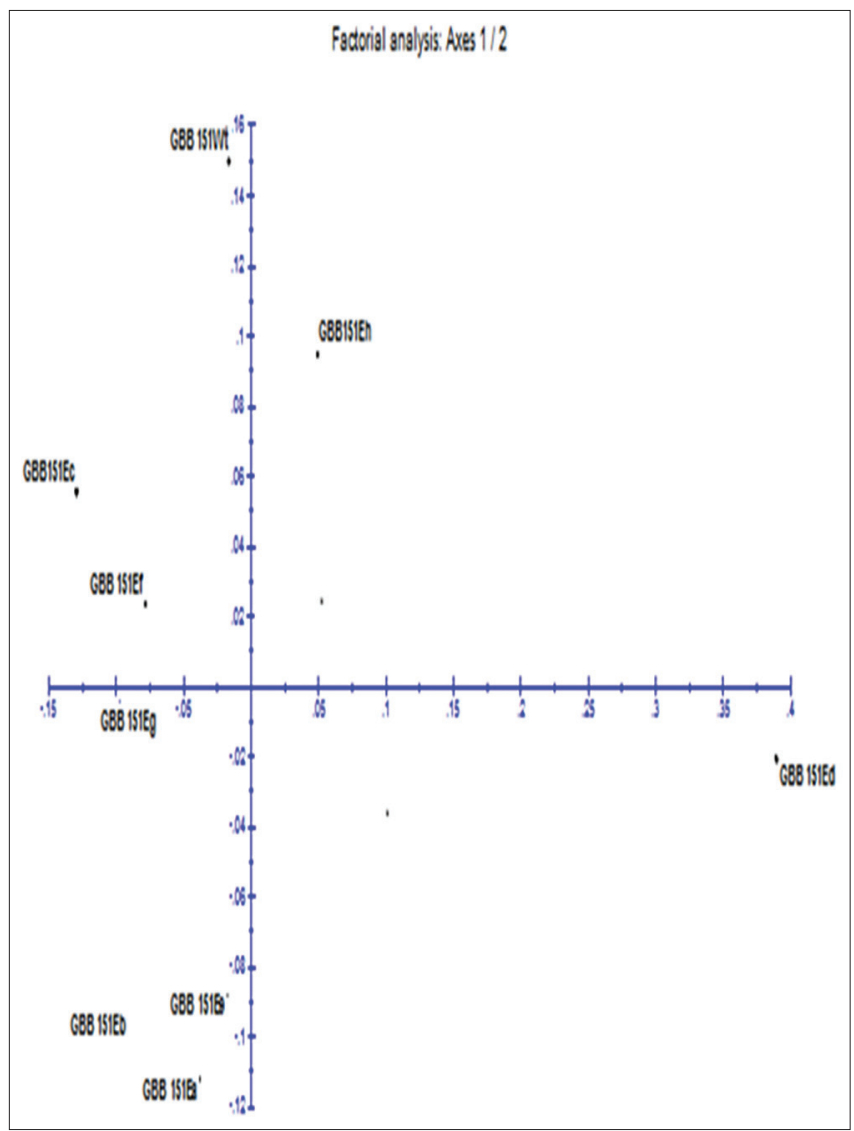

Figure 4: Factorial analysis diagram of GBB151 wild type and mutant strains

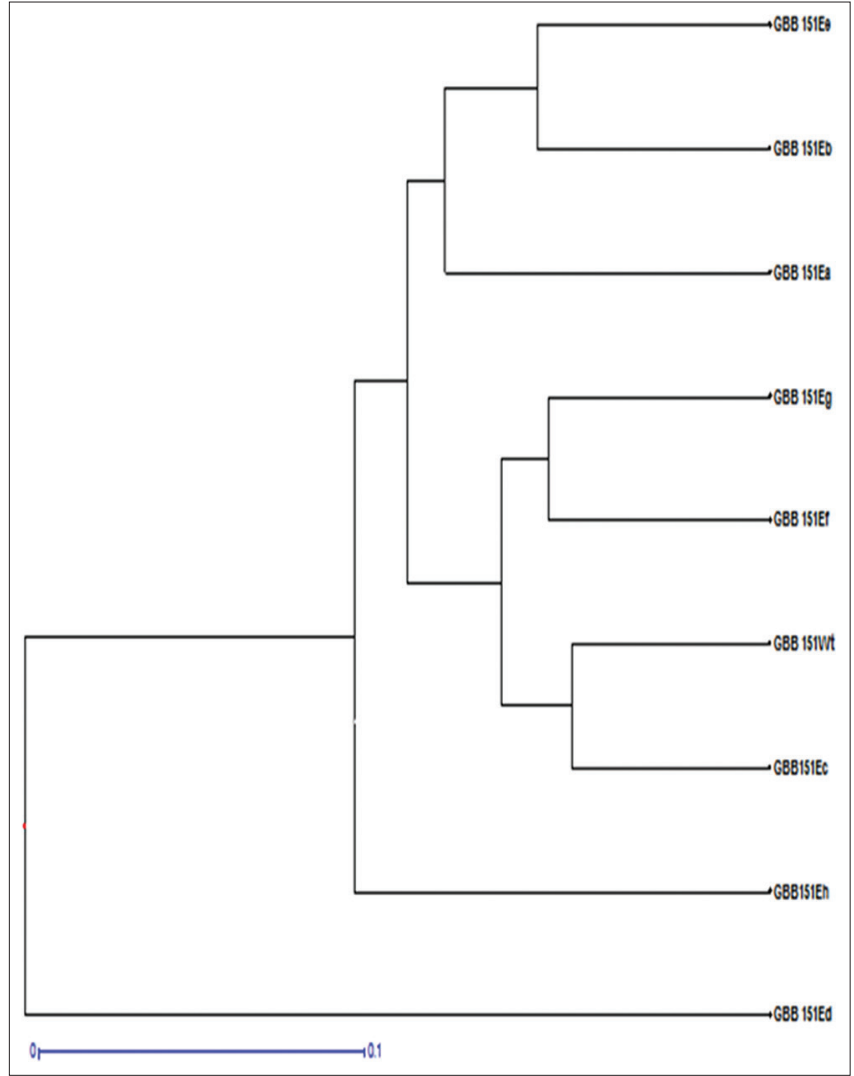

Figure 5: Dendrogram showing the relatedness of GBB151 wild type and mutant strains
It can be deduced from the diagram that mutant strains GBB151Ec and GBB151Ef were closest to the wild type as they appeared in the same quadrant. This implies that few changes occurred in their genetic codes. GBB151Ed which had lost its ability to produce pigment was farthest and in a different quadrant to the wild type, this suggests a high degree of mutation occurring in GBB151Ed which was far more than occurred in all other mutants.

The nucleotide sequences obtained for the wild type and mutants of GBB151 were further analyzed (translated) to reveal the composition of different amino acids (20) contained in the isolates [Supplementary Table S1]. The results showed that glycine (97 in number) was the most common in all the isolates with mutant GBB151Ef having the highest number (15). This was closely followed by leucine (83) and alanine (66). In all the isolates, tyrosine was 22 while methionine was the least amount of 15 . The major differences that occurred in the amino acids of GBB151Ed, the non-pigmented and the other pigmented strains were observed in the number of histidine (6) and threonine (9). These values were higher in GBB151Ed than other strains. Moreover, glycine (7) and arginine (7) had lower values in GBB151Ed than all the other pigmented strains. These variations in the amount of these four amino acids (histidine, threonine, glycine, and arginine) among the non-pigmented (GBB151Ed) and pigmented strains were calculated and found to be statistically significant. Protein function is solely dependent on its amino acid sequence, which then means that a slight change in the amino acid sequence of GBB151 could lead to marked phenotypic changes. The variation in the composition of amino acids in the wild GBB151 and mutants, therefore, supports the function structure relationship of amino acid sequence protein chemistry. More so, the decrease and increase observed in glycine and histidine composition, respectively, in GBB151Ed strain could slightly change the amino acid sequence from non-polar to positively charged or polar sequence which is also in tandem with significant $(P<0.05)$ increase in threonine, a polar amino acid. This change in charges could, in turn, be responsible for bleaching of pigment in GBB151Ed as compared to the wild type.

\section{CONCLUSION}

It has been established in this study that pigment-producing bacteria were isolated from the environment and modified into new strains that were able to produce higher yields of the pigments. The chemical mutants of $S$. marcescens obtained produced 5-fold more pigment than produced by the wild-type organism. RAPD analysis can be, therefore, recommended as an efficient tool for detecting genetic diversity among genotypes.

\section{REFERENCES}

1. Carvalho JC, Pandey A, Babitha S, Soccol CR. Production of Monascus biopigments: An overview. Agro Food Ind Hi Tech 2003;14:37-42.

2. Sajilata MG, Singhal RS. Isolation and stabilization of natural pigments for food applications. Stewart Postharvest Rev 2006;5:1-29.

3. Mapari SA, Nielsen KF, Larsen TO, Frisvad JC, Meyer AS, Thrane $\mathrm{U}$, et al. Exploring fungal biodiversity for the production of water-soluble pigments as potential natural food colorants. Curr Opin Biotechnol 2005;16:231-8.

4. Lu Y, Wang L, Xue Y, Zhang C, Xing XH, Lou K, et al. Production of violet pigment by a newly isolated psychotropic bacterium from a glacier in Xinjang. China Biochem Eng J 2009;43:135-41.

5. Kim CH, Kim SW, Hong SI. An integrated fermentation separation process for the production of red pigment by Serratia Sp. KH-95. Process Biochem 1999;35:485-90.

6. Dharmarcy S, Ashokkumar B, Dhevendaran K. Food-grade pigments 
from Streptomyces Sp. Isolated from marine sponge Callyspongia diffusa. Food Res Int 2009;42:487-92.

7. Cho YJ, Park JP, Hwang HJ, Kim SW, Choi JW, Yun JW, et al. Production of red pigment by submerged culture of Paecilomyces sinclairii. Lett Appl Microbiol 2002;35:195-202.

8. Raisainen R, Nousicienn P, Hynninen PH. Demorubin and 5 cholorodermorubin natural anthraquinone carboxylic acids as dyes for wool. Text Res J 2002;72:973-6.

9. Parekh S, Vinci VA, Strobel RJ. Improvement of microbial strains and fermentation processes. Appl Microbiol Biotechnol 2000;54:287301.

10. Gulani C, Bhattacharya S, Arijat D. Assessment of process parameters influencing the enhanced production of prodigiosin from Serratia marcescens and evaluation of its antimicrobial antioxidant and dyeing potentials. Malays J Microbiol 2012;8:116-22.

11. Sudhakar T, Karpagam S, Shiyama S. Analysis of pyocyanin and its antagonistic activity against phytopathogens. Int J Chem Tech Res 2013;5:1101-6.

12. Mekhael R, Yousif SY. The role of red pigment produced by Serratia marcescens as antibacterial plasmid curing agent. J Duhok Univ 2009;12:268-74.

13. Trindade LC, Marques E, Lopes DB, Ferreira MA. Development of a molecular method for detection and identification of Xanthomonas campestris Pv. viticola. Summa Phytopathol 2007;33:16-23.

14. Shakibare MR, Mansouri S, Hakak S. Plasmid pattern of antibiotic resistance in beta lactamase producing Staphylococcus aureus isolated from hospital in Karman, Iran. J. Antimicrob. Chemother 2002;6:1-4.

15. Akortha EE, Filgona J. Transfer of gentamicin resistance genes among Enterobacteriaceae isolated from the outpatients with urinary tract infections attending 3 hospitals in Mubi, Adamawa State. Sci Res Essay 2009;4:745-52.
16. Das G, Changkija B, Sarkar S, Das P. Genotyping of Cryptosporidium parvum isolates in bovine population in Kolkata and characterization of new bovine genotypes. Res Vet Sci 2011;91:246-50.

17. Linawati H, Anwar H, Colwell R. The influence of environmental condition on the production of pigment by Serratia marcescens. Biotechnol Bioprocess Eng 2002;7:100-4.

18. Sreeju SN, Babu MM, Mariappan C, Selvamohan T. Effect of physical and chemical mutagens on biopolymer producing strains and RAPD analysis of mutated strains. Arch Appl Sci Res 2011;3:233-46.

19. Shazia S, Rukhsana B, Sobiya S. Strain improvement in Trichoderma viride through mutation for overexpression of cellulase and characterization of mutants using random amplified polymorphic DNA (RAPD). Afr J Biotechnol 2011;10:19590-7.

20. Azin DA, Noroozi RF. Effect of chemicals on the improved gluconate productivity by an Aspergillus niger strain. Appl Biochem Biotechnol 2001;61:393-7.

21. Mohsin MJ. Improvement of a Thermophilic Fungal Strain for Cellulase Production by Chemical and UV Mutagenesis, Ph. D. Thesis. Lahore: Department of Botany. GC University; 2006.

22. Hamad A, Haq I, Qadeer MA, Javed I. Screening of Bacillus licheniformis mutants for improved production of alpha-amylase. Pak J Bot 2001;33:517-25.

23. Kawar PG, Devarumath RM, Nerkar Y. Use of RAPD markers for assessment of genetic diversity in sugarcane cultivars. Indian J Biotechnol 2008;8:67-71.

How to cite this article:

Fakorede CN, Itakorode BO, Odeyemi O, Babalola G. Enhancement of pigment production potential of Serratia marcescens (GBB1)

through mutation and random amplified polymorphic deoxyribonucleic acid analysis of its mutants. J App Biol Biotech. 2019;7(04):1-6.

DOI: $10.7324 / J A B B .2019 .70401$ 